\title{
Morphology and mechanical properties of polyamide 12 (PA12)/poly(vinylidene fluoride) (PVDF) blends
}

\author{
Aleksandra M. Ratajska ${ }^{1}$, Wojciech P. Kulak ${ }^{1}$, Artur Poeppel ${ }^{2}$, Andreas Seyler ${ }^{2}$, \\ Zbigniew Roslaniec ${ }^{1, *}$ \\ 1 West Pomeranian University of Technology, Szczecin, Institute of Materials Science and Engineering, Piastów 19, \\ 70-310 Szczecin, Poland \\ ${ }^{2}$ Veritas AG, D-62571 Gelnhausen, Germany \\ * Corresponding author: e-mail: zbigniew.rozlaniec@zut.edu.pl
}

\begin{abstract}
The morphology, thermal and mechanical properties of polyamide 12 (PA12)/poly(vinylidene fluoride) (PVDF) blends were investigated. These polymers are engineering, semi-crystalline polymers which are reciprocally immiscible. Differential scanning calorimetry (DSC), dynamic mechanical thermal analysis (DMTA) and scanning electron microscopy (SEM) were used to characterize the polymeric materials. Mechanical properties were examined by static tensile test. The investigations demonstrate that blends with higher amount of PVDF, with the morphology of two co-continuous semicristalline phases, exhibit better mechanical properties. The blends with small content of PVDF and prepared by extrusion show the morphology of small separated domains of PVDF and full continuous PA phase. The morphology of these blends is different than the blends prepared by internal mixer and have better mechanical properties too. Thus they can be used in particular applications without a compatibilizing agent.
\end{abstract}

Keywords: blends, miscibility, polyamide 12 (PA12), poly(vinylidene fluoride) (PVDF), DSC, DMTA, SEM, mechanical properties.

\section{INTRODUCTION}

Manufacturing of polymer blends is a developing branch of the plastics industry. Very often the only way to obtain a material with desired properties, is blending of two polymers. The main purpose of preparing polymer blends is to achieve a synergetic effect in resulting material (material exhibits better properties than the properties of polymers used as ingredients). Sometimes it is necessary to introduce an additive which improves the miscibility of blend components ${ }^{\mathbf{1}, \mathbf{2}}$.

Both polyamide 12 (PA12) and poly(vinylidene fluoride) (PVDF) are engineering, semi-crystalline polymers $\left(\mathrm{T}_{\mathrm{m}}\right.$ equals $180^{\circ} \mathrm{C}$ and $167^{\circ} \mathrm{C}$ respectively $\left.{ }^{3-4}\right)$. They are used in many applications (technical products, fuel pipes, membranes etc.) due to their good mechanical properties. PVDF additionally demonstrates very good chemical resistance for many agents and is used as hydrogen barrier. Blending of these two polymers may provide interesting results. A blend of this type has been investigated recently by Yoon and Kim in terms of dynamic mechanical, morphological, rheological and thermal properties and interesting results were obtained owing to compatibilization ${ }^{5}$.

PA12 and PVDF blends with other polymers were also

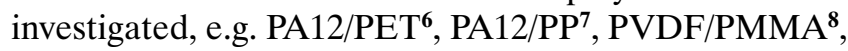
PVDF/PA6 ${ }^{9}$. However, these investigations were focused on the morphology and its influence on crystallization mechanism and physical properties, resulting from the used compatibilizing and nucleation agents.

The purpose of this work was to examine the morphology but as well mechanical properties of PA12/PVDF blends. These blends were prepared without compatibilizing agents by two different methods which influenced the morphology and further, the mechanical properties of the blends.

\section{EXPERIMENTAL}

\section{Materials}

Polyamide 12 - Vestamid HIPHL (DIN 73378), Degussa. The material is plasticized, impact modified, light and thermal stabilized. Poly(vinylidene fluoride) Dyflor X7394, Degussa.

\section{Preparation of samples}

Blends were prepared using two different mixers: an internal mixer and a co-rotating twin-screw extruder, Leistritz LSM 30.34. Prior to blending, polymers were dried at $100^{\circ} \mathrm{C}$ for 2 hours in a vacuum oven.

The material was blended in an internal mixer at $210^{\circ} \mathrm{C}$ for 10 minutes without protecting atmosphere of inert gas. After blending, blends were grinded. Due to small amount of produced blend (about $40 \mathrm{~g}$ ) it could not be moulded into dumbbell specimens. Thus, for the examination of mechanical properties in a static tensile test, films $(0,6-$ $0,8 \mathrm{~mm}$ ) were prepared. In order to measure the hardness, discs were obtained by compression moulding at about $210^{\circ} \mathrm{C}$ to examine the blends morphology by means of scanning electron microscopy, disc shaped specimens were fractured in liquid nitrogen.

As difficulties occurred during extrusion of blends with higher PVDF content, the processing temperatures had to be raised by $5^{\circ} \mathrm{C}$ on each heater, and the screws rotation speed was decreased from $10-15$ to $5 \mathrm{rpm}$. The extruded material was granulated and then dried at $100^{\circ} \mathrm{C}$ for 2 hours in a vacuum oven. To examine the mechanical properties, specimens in the shape of dumbbells were prepared using Dr. Boy 15 injection moulding machine, with the following parameters adjusted:

- Cylinder temperature range: $180 \div 210^{\circ} \mathrm{C}$,

- Mould temperature: $80 \div 90^{\circ} \mathrm{C}$,

- Injection pressure: $60 \mathrm{MPa}$. 
To carry out thermal analyses (DSC, DMTA) and to examine the morphology of blends (prepared by mixing and extrusion) using the scanning electron microscopy (SEM) the dumbbell-shaped specimens were used.

Pure bulk polymer pellets of PA12 and PVDF were used to determine the melt volume- flow rate (MVR). Prior to this, the polymers were dried at $100^{\circ} \mathrm{C}$ for 2 hours in a vacuum oven.

\section{METHODS OF INVESTIGATION}

\section{General properties}

During the measurement of MVR (Melt Volume-Flow Rate) (according to ISO 1133 standard) polymers were extruded under the load of $2.16 \mathrm{~kg}$. Polymers in the form of pellets were used. The measurements were carried out at various temperatures ranging from $215^{\circ} \mathrm{C}$ to $235^{\circ} \mathrm{C}$. At each increase of 5 degrees measurements were taken.

The density was determined using a pycnometer and an appropriate laboratory scale. Water was used as an immersion liquid, except for the experiments on pure bulk polyamide. In this case a solution of ethanol was used as an immersion liquid. Five samples of each blend were tested. The resulting average value was used in later calculations. Swelling of polyamide in the liquid was taken into account.

\section{Morphology and thermal properties}

Melting $\left(\mathrm{T}_{\mathrm{m}}\right)$ and crystallization $\left(\mathrm{T}_{\mathrm{c}}\right)$ temperatures of the samples were determined by means of Differential Scanning Calorimetry on TA-Instruments Q100 calorimeter. Samples were heated to $250^{\circ} \mathrm{C}$, subseqently cooled to $10^{\circ} \mathrm{C}$ and then heated again. The temperature was changing at the rate of $10^{\circ} \mathrm{C} / \mathrm{min}$. Only data from the second heating cycle was analysed

Dynamic Mechanical Thermal Analysis (DMTA) was applied to collect important information about relaxation phenomena which occurred in the material as the temperature was increased. The samples were examined using Rheometric Scientific DMTA 3E apparatus. During the experiment samples were stretched at the frequency of $1 \mathrm{~Hz}$ and the rate of heating was set on $3^{\circ} \mathrm{C} / \mathrm{min}$.

A JEOL JSM 6100 scanning electron microscope was used to examine the phase structure of blends. The observations were carried out on samples which were first fractured in liquid nitrogen and vacuum sputtered with gold.

\section{Mechanical properties}

The hardness was examined using a hardness tester type Shore D (according to EN ISO 868 standard). The hardness values were read out from a scale after 3 seconds from the start of experiment.

To carry out the examination of mechanical properties by a static tensile test (according to the EN ISO 527-1 standard), Instron tensile testing machine was used. The grips movement rate was set on $100 \mathrm{~mm} / \mathrm{min}$ for film specimens. For dumbbell specimens the rate was decreased to $50 \mathrm{~mm} / \mathrm{min}$. Based on the results of experiments, the following quantities were calculated: yield stress $\sigma_{\mathrm{Y}}$, tensile strength $\sigma_{\mathrm{M}}$, stress at break $\sigma_{\mathrm{B}}$, strain at yield stress $\varepsilon_{\mathrm{Y}}$, maximum strain $\varepsilon_{\mathrm{M}}$, strain at break $\varepsilon_{\mathrm{B}}$.

\section{RESULTS AND DISCUSSION}

In the present work the morphology, thermal and mechanical properties of polyamide 12 (PA12)/ poly(vinylidene fluoride) (PVDF) blends were examined. The blends were prepared by different methods: in an internal mixer and by extrusion.

\section{General properties}

According to the published works on the subject it is known that PA and PVDF are generally immiscible polymers (solubility parameters: $20-23 \mathrm{MPa}^{0,5}$ and $13 \mathrm{MPa}^{0,5}$ respectively $\left.{ }^{10}\right)$. In order to obtain good properties of the mixture, appropriate components dispersion is needed. One of the conditions that determine a good dispersion is similar viscosity of mixed polymers at the optimum temperature of processing. Measured values of MVR as the function of temperature indicate that difficulties may occur during blending (Fig.1)

The density of blends rises with increasing amount of PVDF (Fig. 2.). The change of overall blend density is associated with the differences of the components density. The results of investigation indicate that blends were prepared properly (there was no degradation of materials

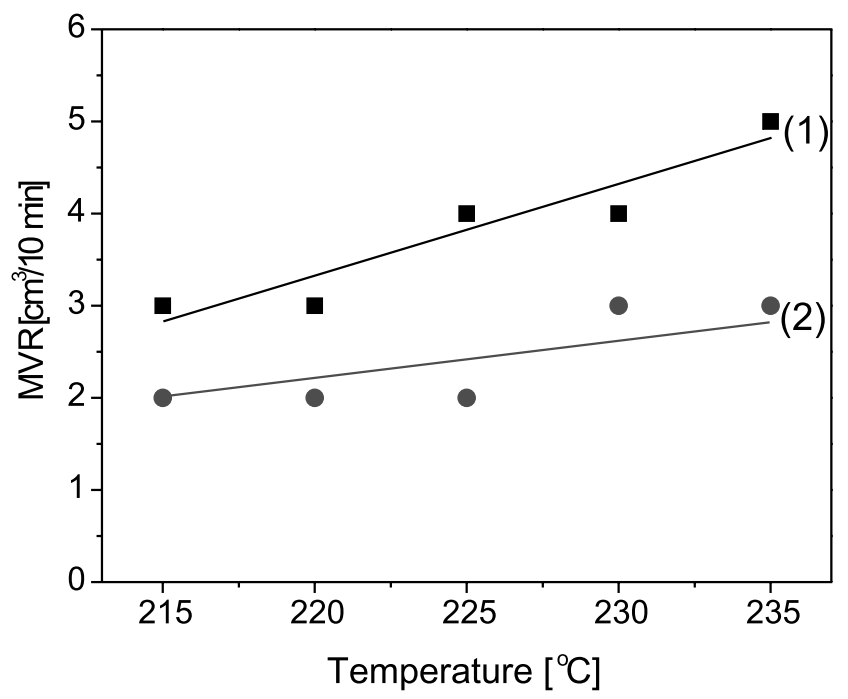

Figure 1. Values of MVR for PA12(1) and PVDF(2) in the function of temperature

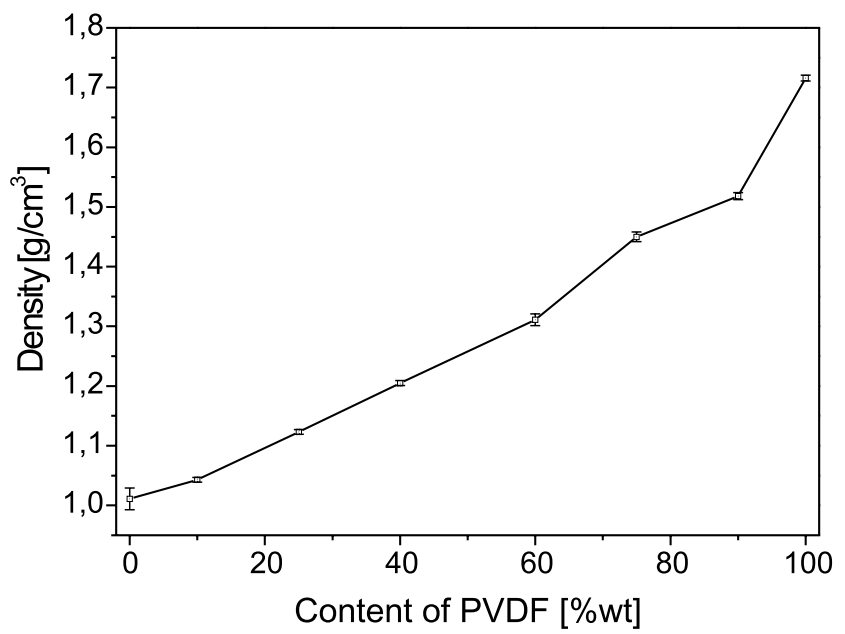

Figure 2. Density of PA12/PVDF blends in the function of PVDF content, for blends prepared in the internal mixer 
during mixing and in general porosity did not result from this process).

\section{Morphology}

In the internal mixer samples of blends covering the full scope of content ratios were prepared. By extrusion, only blends containing up to $20 \mathrm{wt} . \%$ of PVDF were prepared. It was not possible to obtain blends with higher content of PVDF with this method due to problems occurring while blending.

From the comparison of fig. 3 (extruder) and fig. 4 (internal mixer) it is clear that blending in the extruder yields finer size of the dispersed phase and it is possible to obtain smaller domains of PVDF in the PA12 matrix even for the 80/20 PA12/PVDF blend. (Fig. 3). In the case of blends prepared in the internal mixer the size of dispersed phase is larger (Fig 4 PA12 forms very small dispersed phase (about 100nm) which is relatively well dispersed in the blend. When the content of PA12 rises, samples become more heterogeneous and the dispersed phase domains become larger in size. The 60/40 and 75/ 25 PA12/PVDF blends are the most heterogeneous materials, where large dimensions of dispersed PVDF phase can be observed. There are very weak interactions between these domains and the PA12 matrix (fracture cavities after dispersed microphases, see Fig.4b, c). The

a)

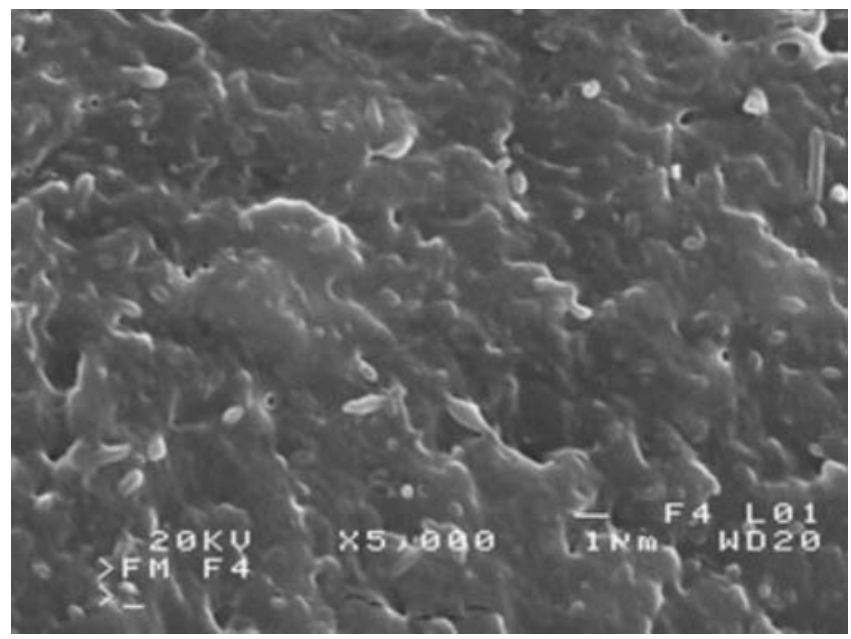

c)

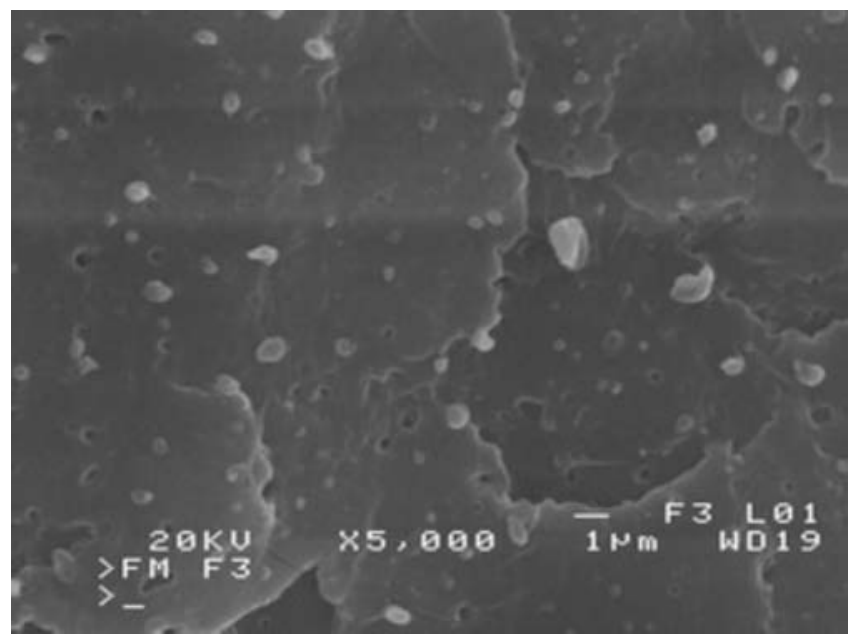

morphology of blends with higher PVDF content (60$75 \mathrm{wt} \%$ ) is different (Fig.4d,e). The blends exhibit a cocontinuous (interpenetrating) two phase system and good phase connection (adhesion, interaction). In the blend with small content of PA 12 (10wt\%, Fig. 4f) the PA phase is well dispersed in the PVDF matrix (spherical micro particles) and good phase connection is observed. It may be a result of high thermal expansion coefficient of $\mathrm{PVDF}^{\mathbf{3}}$. The blends with small content of PVDF and prepared by extrusion possess the morphology with fine separated PVDF domains and full continuous PA phase (Fig. 3). The morphology of this blends is different from the blends prepared by internal mixer.

The DSC results for blends prepared in the mixer, performed under phase equilibrium conditions (2-nd run of DSC) show the morphology of two semicristalline phases (two melting temperatures corresponding to the melting points of components) (Tab.1). For one sample with low PA12 content Tm cannot be observed (amorphous phase or very small heating effect, Fig.5g). Similar effect is seen on the cooling plot (crystallization) (Fig.6). The DSC results for the blends prepared in extruder show one peak but it is not due to miscibility effects (see Fig. 3). It is possible that PA12 partially degraded under extruding conditions, what effected depression of the melting temperature. Melting points and crystallization effects of PVDF

b)

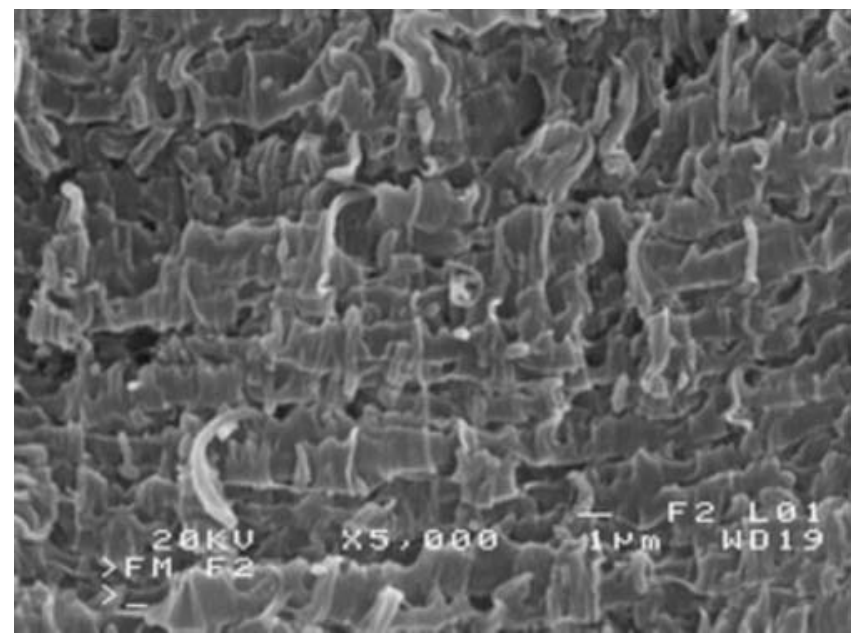

d)

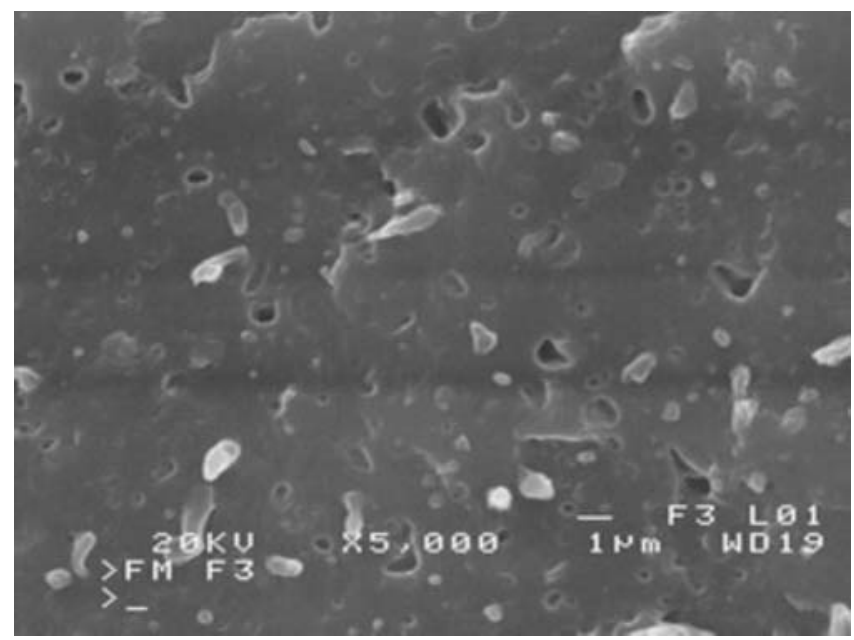

Figure 3. The morphology of the blends prepared by extrusion; following percentage weight ratios of PA12/PVDF: a) 95/05, b) $90 / 10$, c) $85 / 15$, d) $80 / 20$ 
a)

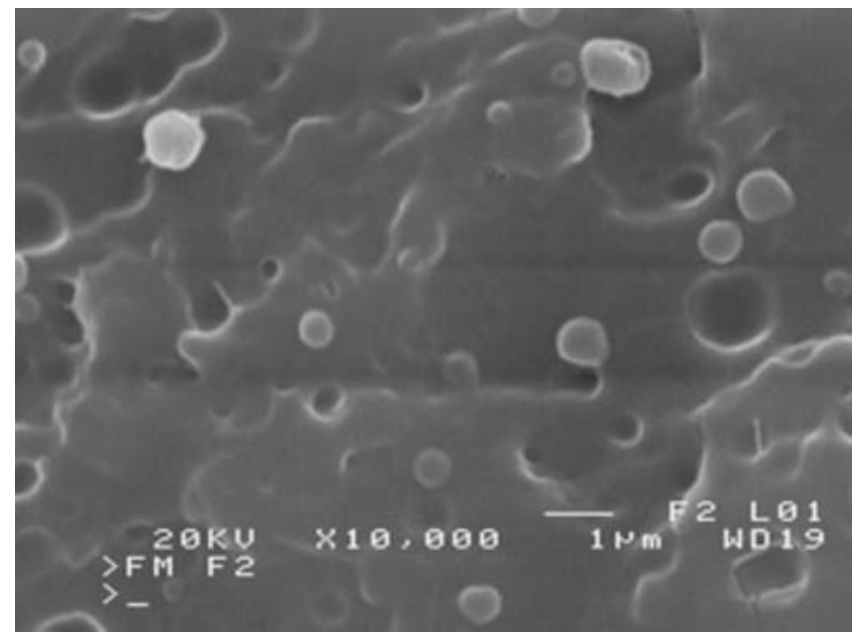

c)

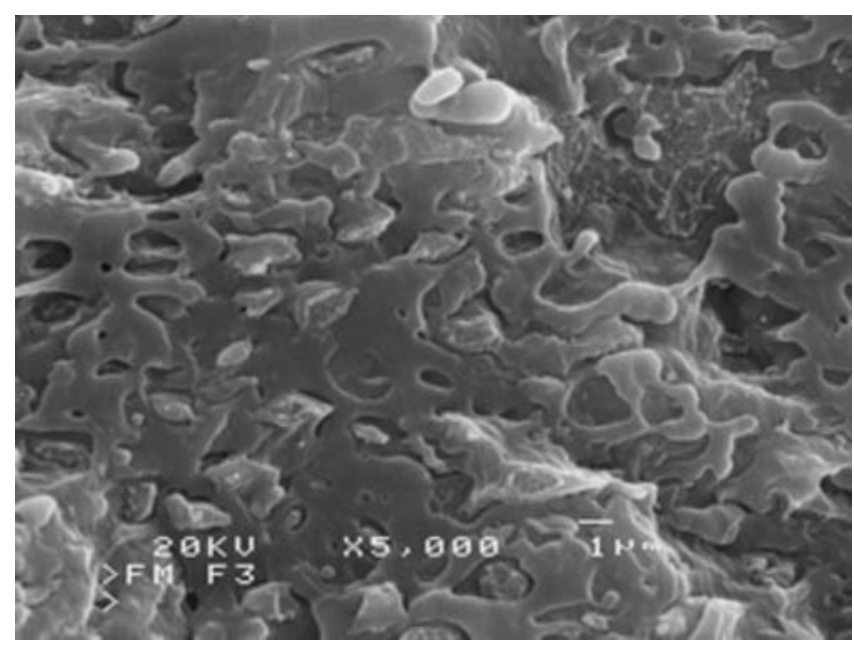

e)

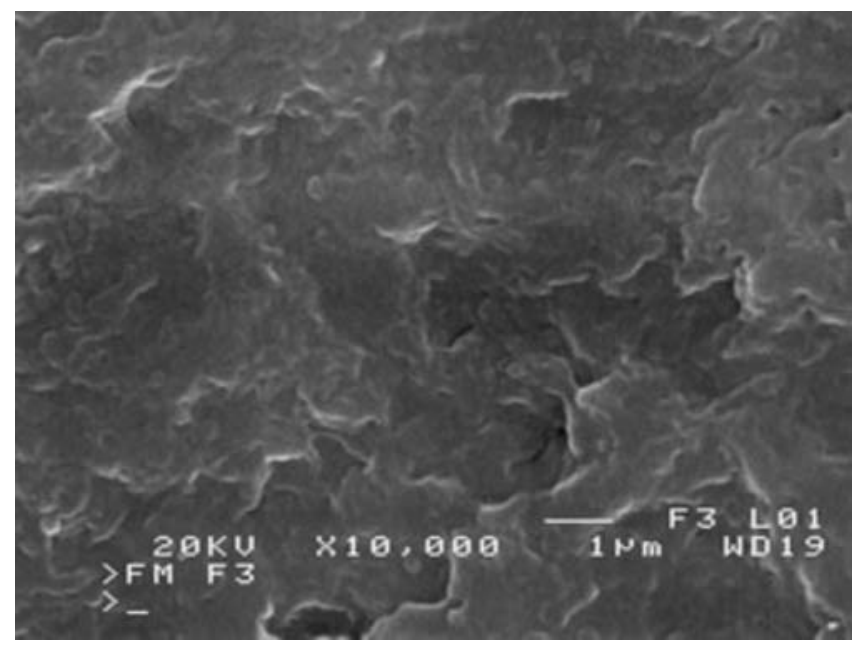

b)

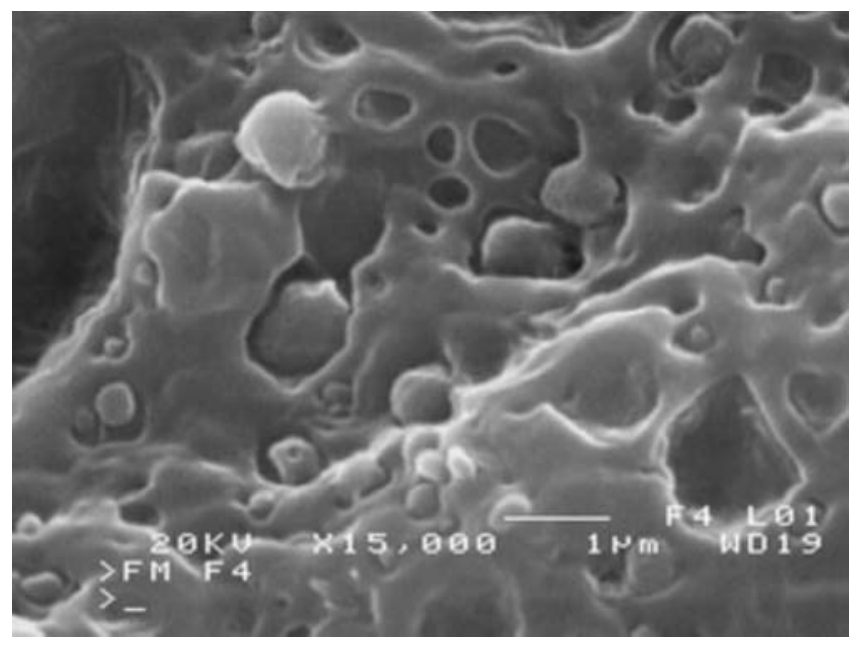

d)

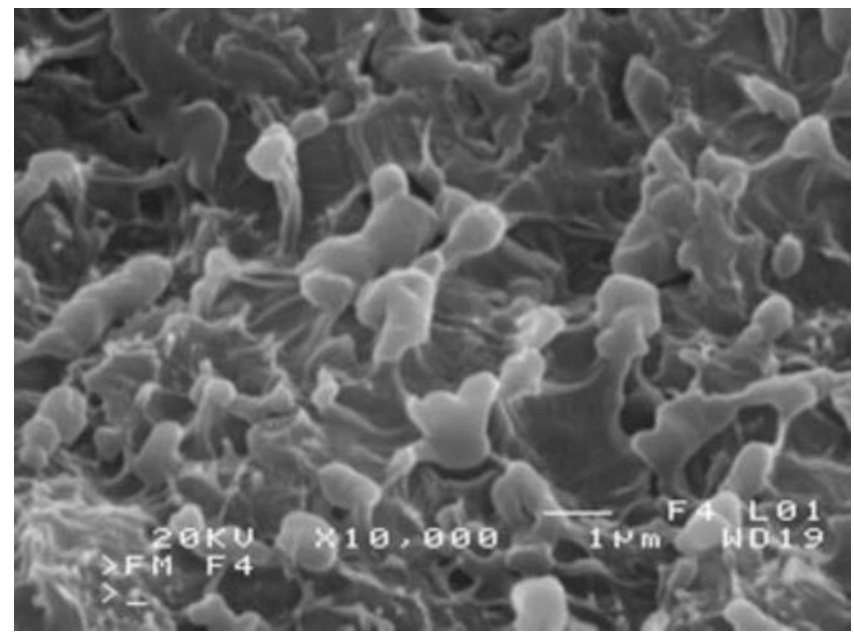

f)

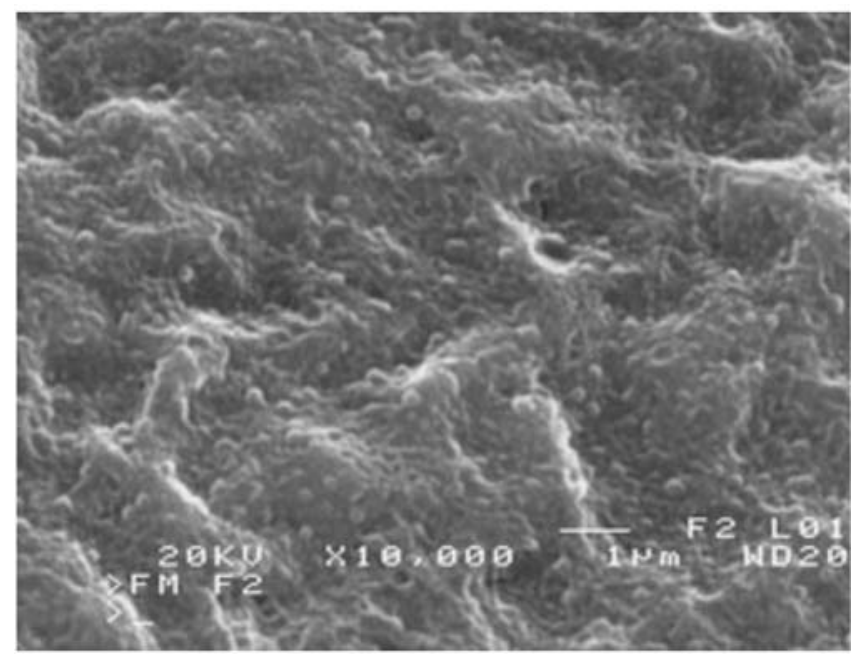

Figure 4. The morphology of the blends prepared in internal mixer; the following percentage weight ratios of PA12/PVDF: a) $90 / 10$, b) $75 / 25$, c) $60 / 40$, d) $40 / 60$, e) $25 / 75$, f) $10 / 90$

and PA12 (Fig. 7 and 8) may have similar values adequately (one peak) ay increase in result of presence of low molecular weight PA in blends too.

Moreover the relaxation temperature ( $\mathrm{T}_{\beta}$ from DMTA) for extruded blends at the percentage weight ratios of PA/ PVDF respectively $95 / 05,90 / 10$ and $85 / 15$ and $80 / 20$ (Fig.9,10) has higher values than $\mathrm{T}_{\beta}$ for pure PA12 (Fig.9 and 10). Probably it is a result of worse components dispersion within this blends and higher interphase interaction forces (partial miscibility). Relaxation temperature of the micro phase in polymer blends (from E" or $\tan \delta$ ), similar as glass transition, is dependent on the phase composition $^{\mathbf{1 0}}$. It is possible that the PA12 phase in the extruded blends (Fig. 10) is composed of PA and a small fraction of amorphous PVDF. 


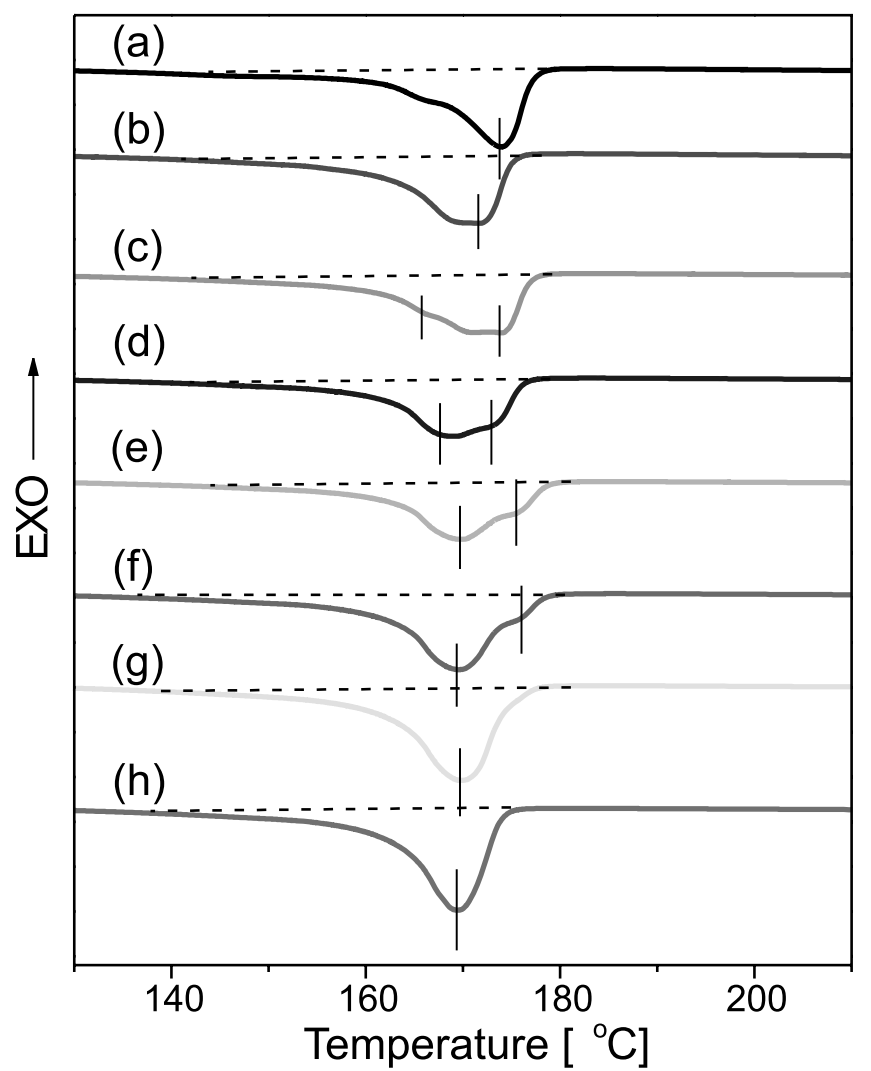

Figure 5. DSC traces for the PA12/PVDF blends prepared in internal mixer; (a)PA12, (b)90/10 PA12/PVDF, (c)75/25 PA12/PVDF, (d)60/40 PA12/PVDF, (e)40/ 60 PA12/PVDF, (f)25/75 PA12/PVDF,(g)10/90 PA12/ PVDF, (h)PVDF; heating rate: $10^{\circ} \mathrm{C} / \mathrm{min}$

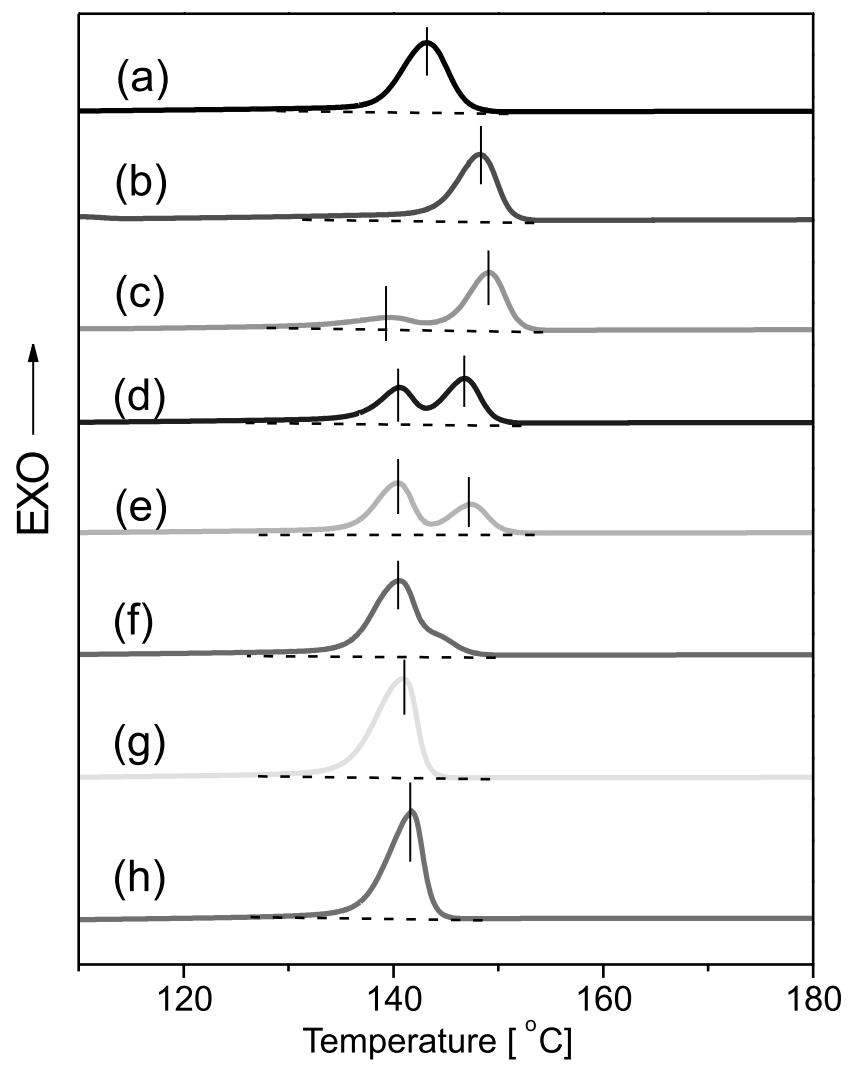

Figure 6. DSC traces for the PA12/PVDF blends prepared in internal mixer; (a)PA12, (b)90/10 PA12/PVDF, (c)75/25 PA12/PVDF, (d)60/40 PA12/PVDF, (e)40/ 60 PA12/PVDF, (f)25/75 PA12/PVDF,(g)10/90 PA12/ PVDF, (h)PVDF; cooling rate: $10^{\circ} \mathrm{C} / \mathrm{min}$

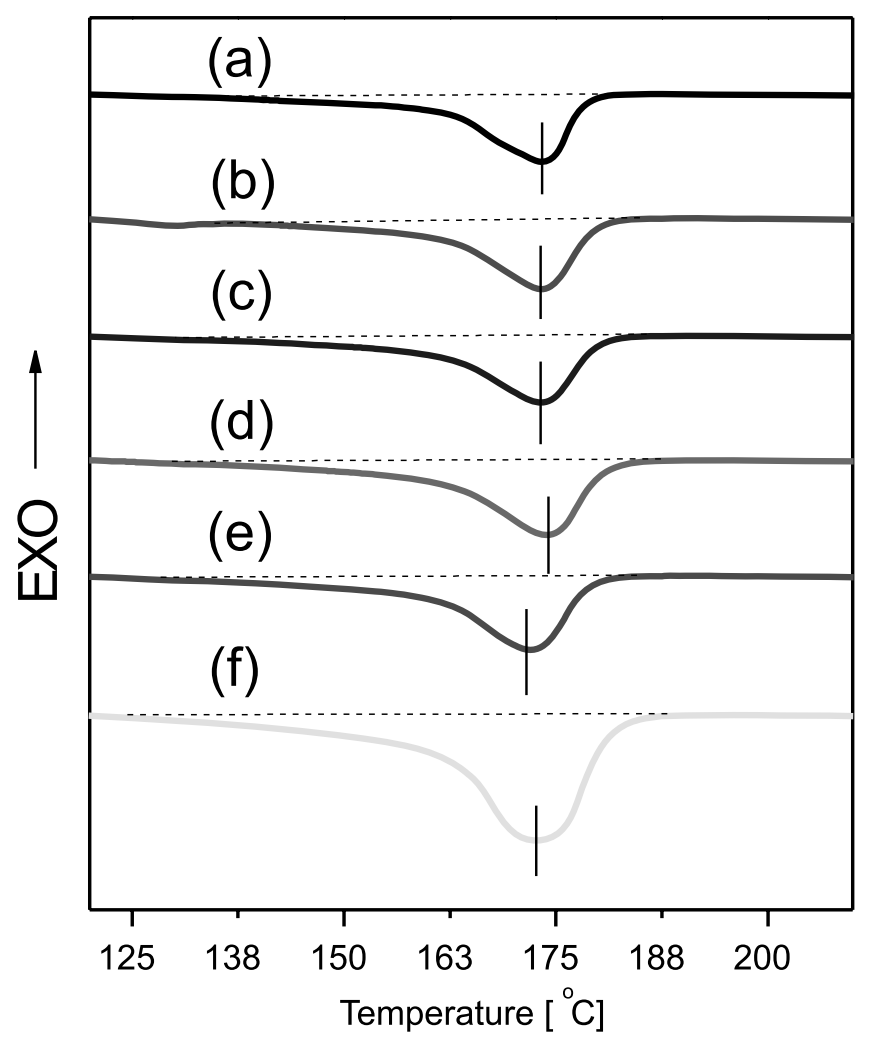

Figure 7. DSC traces for the PA12/PVDF blends prepared by extrusion method; (a)PA12, (b)95/05 PA12/ PVDF, (c)90/10 PA12/PVDF, (d)85/15 PA12/PVDF, (e)80/20 PA12/PVDF, (f)PVDF; heating rate: $10^{\circ} \mathrm{C} /$ $\min$

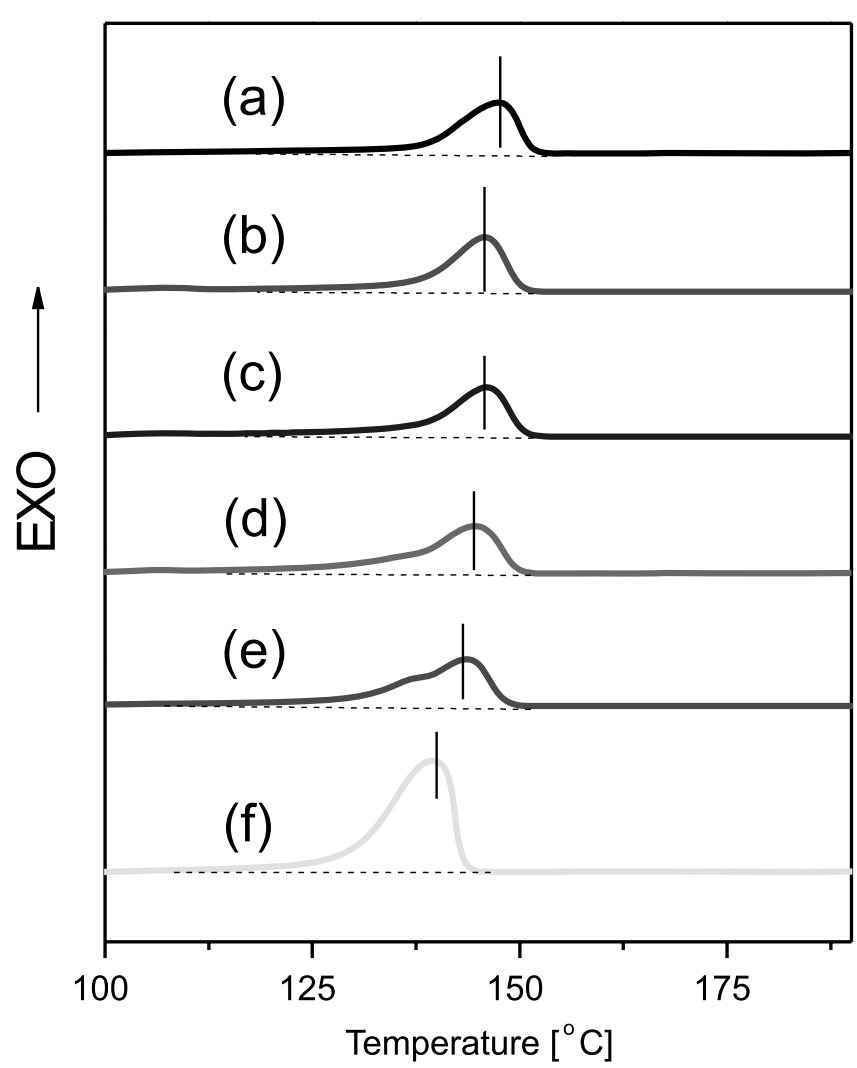

Figure 8. DSC traces for the PA12/PVDF blends prepared by extrusion method; (a)PA12, (b)95/05 PA12/ PVDF, (c)90/10 PA12/PVDF, (d)85/15 PA12/PVDF, (e)80/20 PA12/PVDF, (f)PVDF; cooling rate: $10^{\circ} \mathrm{C} /$ $\min$ 


\section{Mechanical properties}

The hardness of blends generally rises with increasing PVDF content (Fig. 11, 12). Hardness values for blends obtained by extrusion (Fig. 12) increase linearly and results of hardness of blends obtained in internal mixer (Fig.11) show scatter. Probably it is due to higher degree of dispersion (macro homogeneity, no fracture cavities ) of the material. The results of tensile test reveal that the mechanical properties strongly depend on the components dispersion. Better properties are obtained for the blends prepared by extrusion method where higher shear forces are present. The co-continuous morphology effected better results of tensile test too (see 60 and $75 \mathrm{wg} \%$ PVDF, Fig 14 and 15).

The results of examinations of the mechanical properties of blends prepared in the internal mixer indicate that the yield strength increases with the rising content of PVDF. But the highest value is obtained for the 10/90 PA12/PVDF blend, not - as it could be expected - for pure PVDF polymer (Fig. 13). The samples of the 60/40 blend had heterogeneous morphology with interphase fracture cavities. The size of the dispersed phase was different and was visible with the naked eye. Most of the samples with this composition broke immediately after the commencement of test.

Both tensile strength and stress at break of the 90/10 PA12/PVDF blend are higher than the respective values obtained for pure polymers (Fig. 14 and 15). Similar situation is present in the case of the maximum elongation $\varepsilon_{\mathrm{M}}$ and elongation at break $\varepsilon_{\mathrm{B}}$; the values obtained for this blend are also higher than the values for pure polymers. The worst mechanical properties (especially $\sigma_{\mathrm{M}}, \sigma_{\mathrm{B}}, \varepsilon_{\mathrm{M}}$ and $\varepsilon_{\mathrm{B}}$ ) revealed the blend with percentage weight ratio 60/40 PA12/PVDF. Surprisingly, the next blend (of percentage weight ratio 40/60) revealed much better properties.

The examination of mechanical properties of blends obtained by extrusion widens the view of blends with low PVDF content in the PA12 matrix. It can be observed that the values of yield strength and strain by yield strength strongly increase with the rising content of PVDF until $15 \mathrm{wt} \%$. Above this content, the mechanical properties start to decrease (Fig. 16). Similar situation can be observed in the case of tensile strength. Again the highest value is obtained for the 85/15 PA12/PVDF blend (Fig. 17). The value of maximum elongation is the highest for the pure PA12. The shape of curves obtained for $\sigma_{\mathrm{B}}$ and $\varepsilon_{\mathrm{B}}$ does not vary much from the shape of the $\sigma_{\mathrm{M}}$ and $\varepsilon_{\mathrm{M}}$ curves. The $85 / 15$ blend reveals the highest stress at break

Table 1. Thermal properties of PA12/PVDF blends obtained by mixing in internal mixer from DSC investigation

\begin{tabular}{|c|c|c|c|c|c|}
\hline & & $\begin{array}{c}\mathrm{T}_{\mathrm{m}} \\
{\left[{ }^{\circ} \mathrm{C}\right]}\end{array}$ & $\begin{array}{l}\Delta \mathrm{H}_{\mathrm{m}} \\
{[\mathrm{J} / \mathrm{g}]}\end{array}$ & $\begin{array}{c}\mathrm{T}_{\mathrm{c}} \\
{\left[{ }^{\circ} \mathrm{C}\right]}\end{array}$ & $\begin{array}{c}\Delta \mathrm{H}_{\mathrm{c}} \\
{[\mathrm{J} / \mathrm{g}]}\end{array}$ \\
\hline \multirow{8}{*}{ 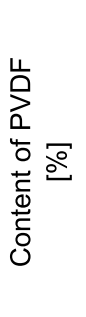 } & 0 & 174 & 42 & 143 & 44 \\
\hline & 10 & 171 & 43 & 148 & 43 \\
\hline & 25 & 166,174 & 42 & 139,149 & 44 \\
\hline & 40 & 168,173 & 43 & 140,147 & 42 \\
\hline & 60 & 169,175 & 40 & 140,147 & 41 \\
\hline & 75 & 169,176 & 42 & 140 & 44 \\
\hline & 90 & 169 & 44 & 141 & 45 \\
\hline & 100 & 169 & 46 & 142 & 44 \\
\hline
\end{tabular}

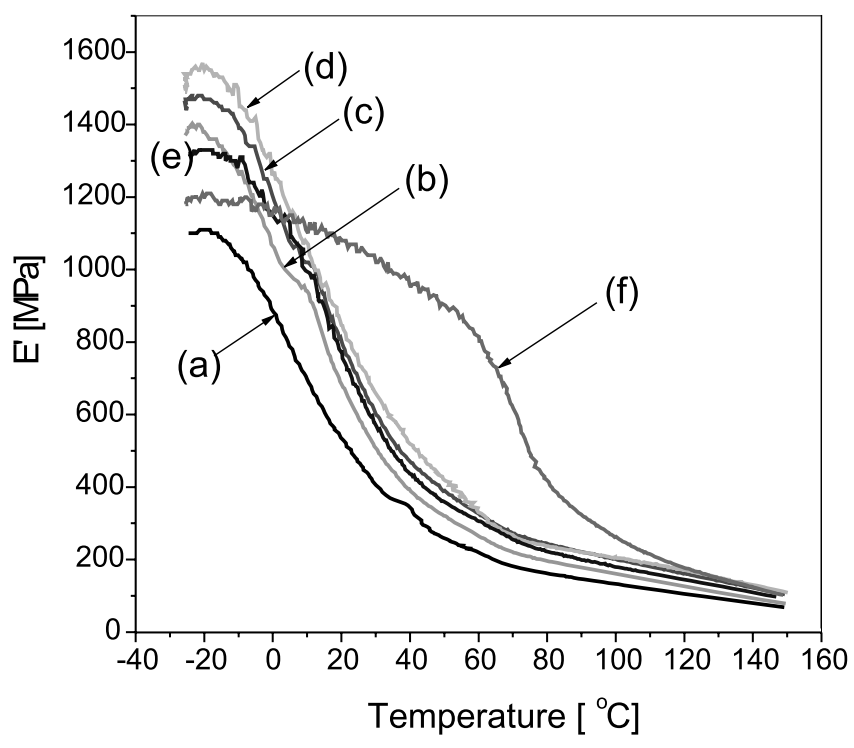

Figure 9. Traces from DMTA analysis for storage modulus E' of PA12/PVDF blends; (a)PA12, (b)95/05 PA12/ PVDF, (c)90/10 PA12/PVDF, (d)85/15 PA12/PVDF, (e)80/20 PA12/PVDF, (f)PVDF; stretching frequency: $1 \mathrm{~Hz}$

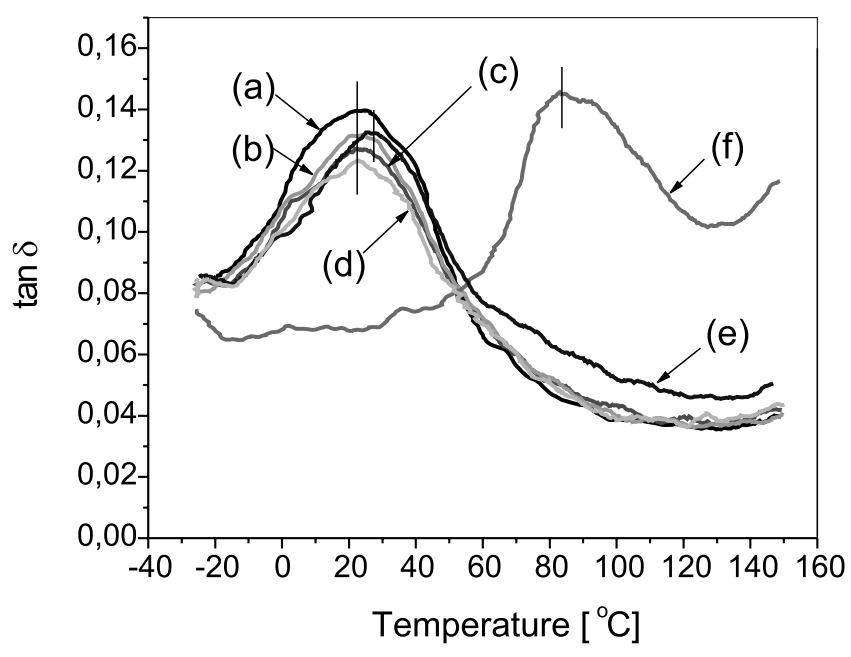

Figure 10.Traces from DMTA analysis for loss tangent $(\tan \delta)$ of PA12/PVDF blends; (a)PA12, (b)95/05 PA12/ PVDF, (c)90/10 PA12/PVDF, (d)85/15 PA12/PVDF, (e)80/20 PA12/PVDF, (f)PVDF; stretching frequency: $1 \mathrm{~Hz}$

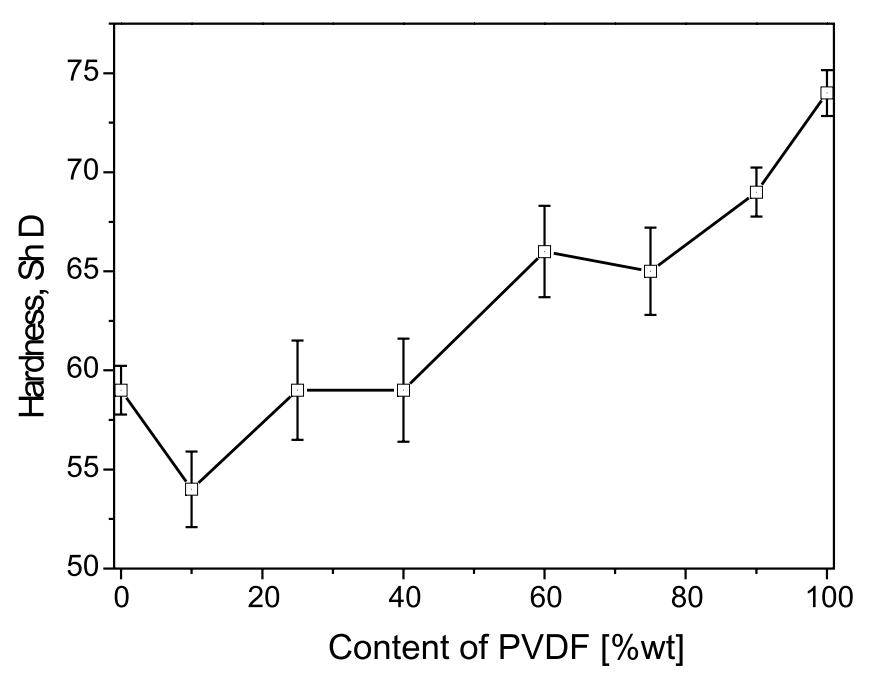

Figure 11. The hardness of PA12/PVDF blends as a function of content of PVDF for blends prepared in internal mixer 


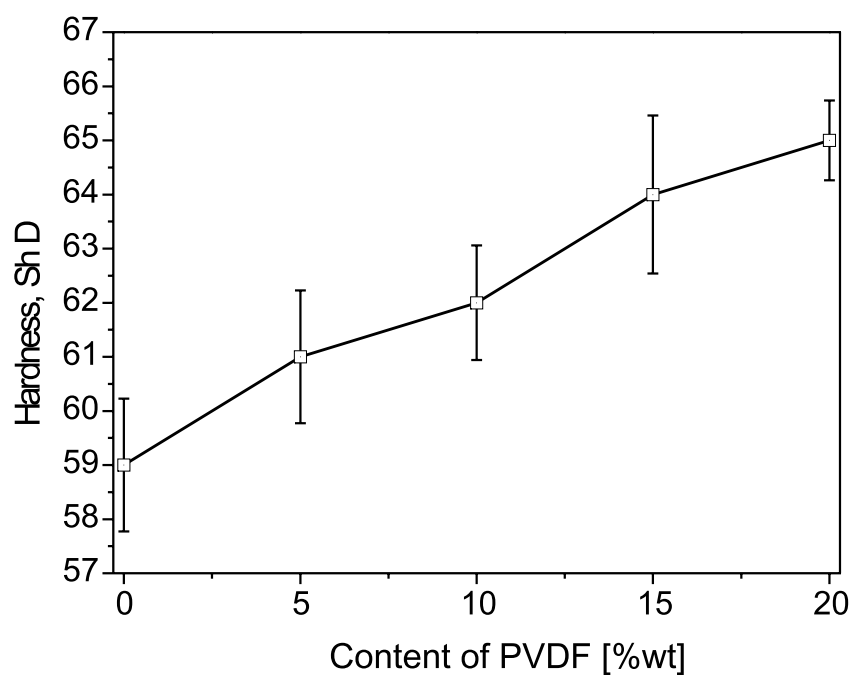

Figure 12. The hardness of PA12/PVDF blends as a function of content of PVDF, for blends prepared by extrusion method

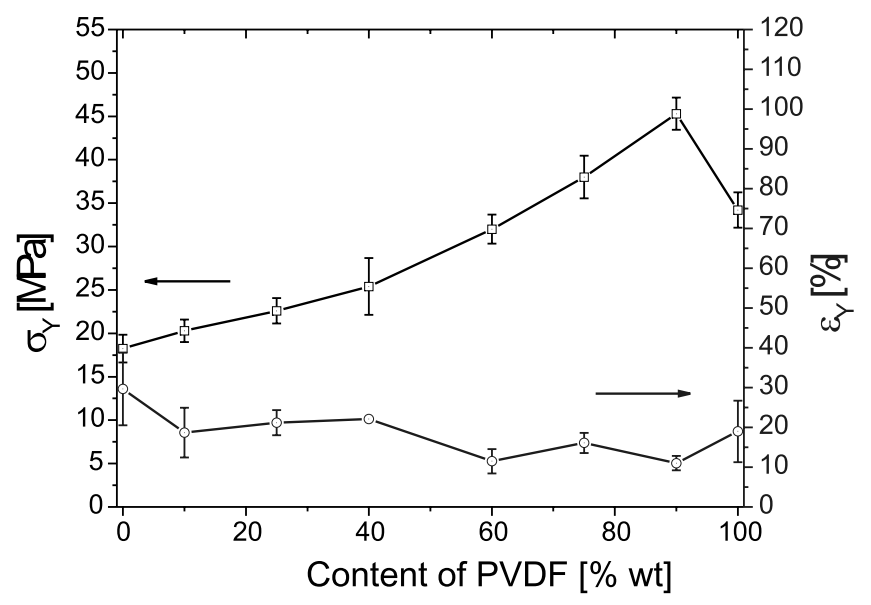

Figure 13. The yield stresss $\left(\sigma_{\mathrm{Y}}\right)$ and strain by yield stress $\left(\varepsilon_{\mathrm{Y}}\right)$ in the function of content of PVDF, for PA12/PVDF blends prepared in the internal mixer

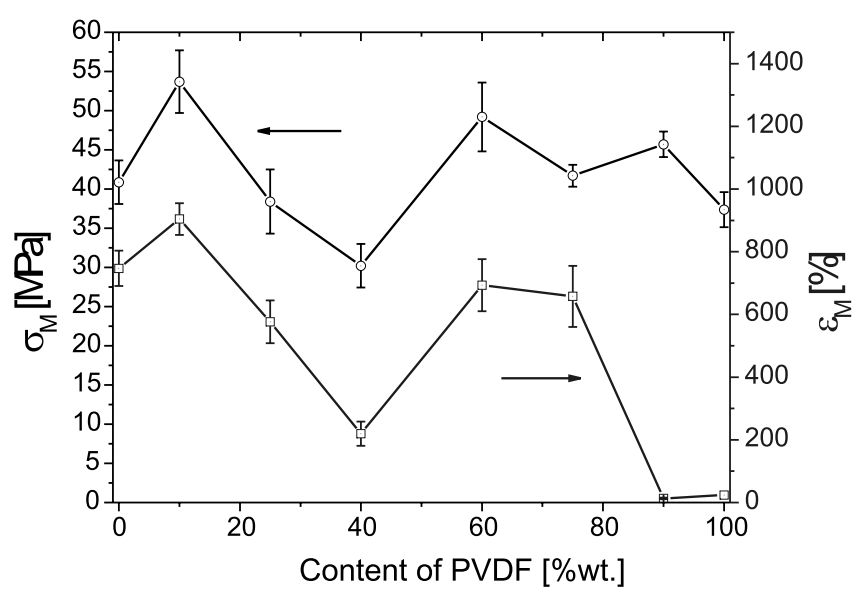

Figure 14. The tensile strength $\left(\sigma_{\mathrm{M}}\right)$ and maximum elongation $\left(\varepsilon_{\mathrm{M}}\right)$ in the function of content of PVDF, for PA12/ PVDF blends prepared in the internal mixer

but the highest elongation at break is observed for the pure PA12 (Fig. 18).

It is clear that the mechanical properties of PA12/PVDF blends depend on the homegenous distribution of the dispersed phase or specific co-continuous morphology.

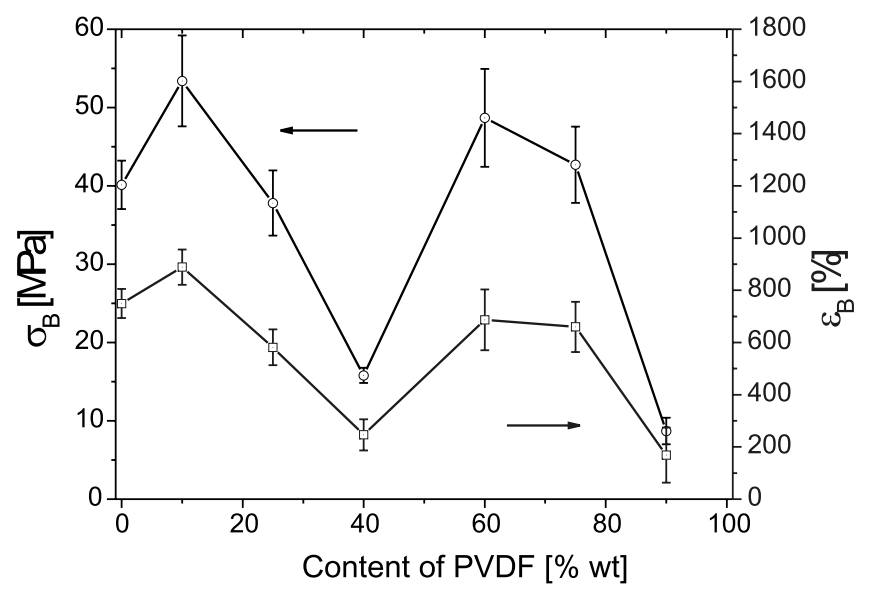

Figure 15. Stress at break $\left(\sigma_{\mathrm{B}}\right)$ and strein at break $\left(\varepsilon_{\mathrm{B}}\right)$ in the function of content of PVDF, for PA12/PVDF blends prepared in the internal mixer

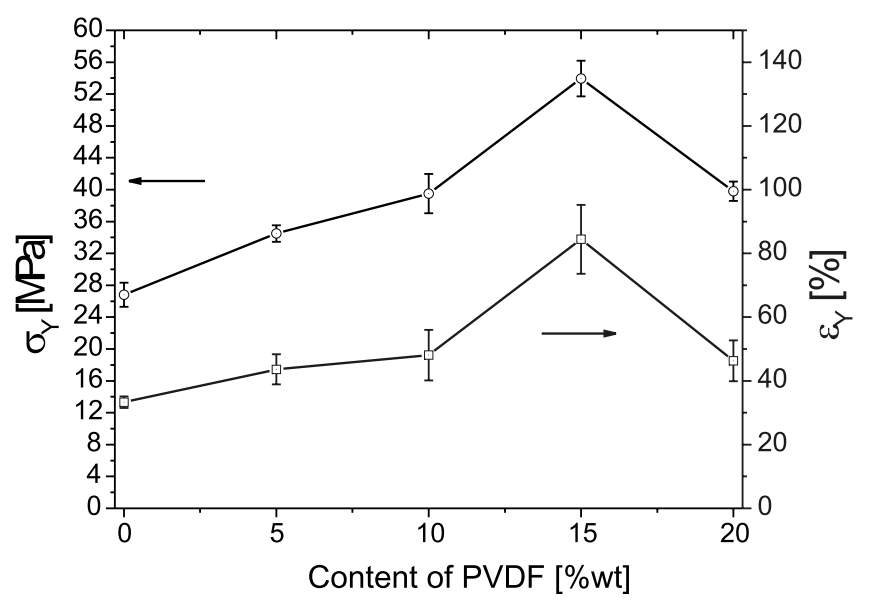

Figure 16. The yield strength $\left(\sigma_{Y}\right)$ and strain by yield strength $\left(\varepsilon_{\mathrm{Y}}\right)$ in the function of content of PVDF, for PA12/ PVDF blends prepared by extrusion method.

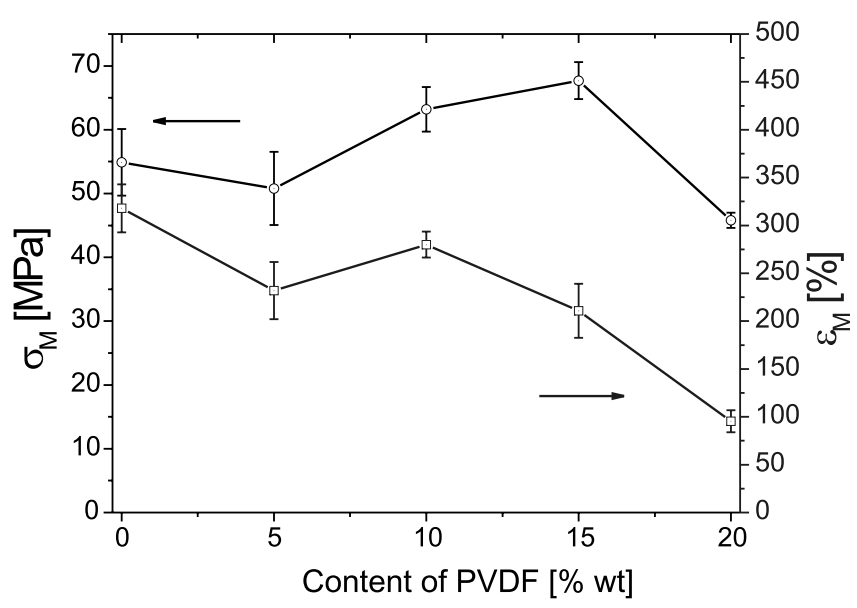

Figure 17. The tensile strength $\left(\sigma_{\mathrm{M}}\right)$ and maximum elongation $\left(\varepsilon_{\mathrm{M}}\right)$ in the function of content of PVDF for PA12/ PVDF blends prepared by extrusion method

\section{CONCLUSIONS}

The investigated PA12 and PVDF are immiscible. It is confirmed by the results of various examinations. However, some blends of these two polymers without compatibilizing agents reveal better mechanical properties in the windows of their concentration. For example the properties of blends with low amount of PVDF (5 - 


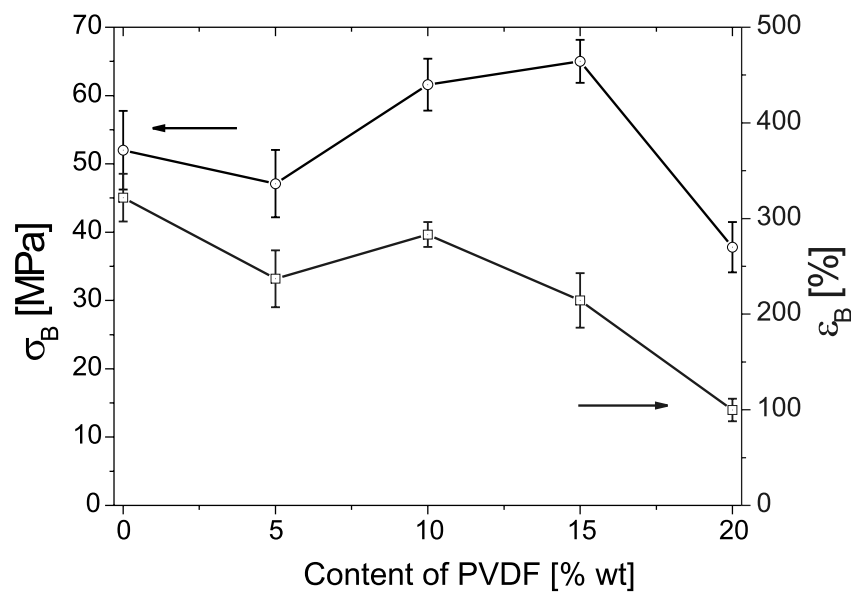

Figure 18. Stress at break $\left(\sigma_{\mathrm{B}}\right)$ and elongation at break $\left(\varepsilon_{\mathrm{B}}\right)$ in the function of content of PVDF, for PA12/PVDF blends prepared by extrusion method

15wt.\% PVDF), especially tensile strength and stress at break, are better than those obtained for pure polymers used as components but an intensive processing (dispersing) method should be used. The co-continuous morphology of dispersed components sometimes yields increased material strength.

As the PA12 content becomes predominant in blends (60/40 and $75 / 25 \mathrm{wt} . \%)$ the mechanical properties are considerably affected. The method of blending strongly influences the structure and thus the properties of material. Materials obtained by extrusion possess small size, round domains of the dispersed phase in their structure. These domains are smaller than those obtained by blending in the internal mixer. The blends from extruder revealed quite good properties, which often were better than the properties of pure polymers.

Small difference between melting and crystallization temperatures of these two polymers can facilitate the preparation of blends with good mechanical properties.

Summarizing, the blends with low amount of PVDF, which is well dispersed in the PA12 matrix and has the shape of small spherical domains or exhibits a co-continuous morphology reveal good mechanical properties. Thus they can be used in particular applications, e.g. it can be a method of recycling scrap from fuel hose production lines and double layer systems with interlayer diffusion sealed connection to fuel cell and hydrogen barrier films.

\section{ACKNOWLEDGEMENT}

The work is a part of the research programme of Polish Ministry of Science and Higher Education, project PBZKBN-117/T08 in $2006-2008$.

\section{LITERATURE CITED}

1. Zdrazilowa, N., Hausnerova, B., Kitano, T. \& Saha, P. (2004). The role of various modifiers in the compatibilisation of PP/PET blends - rheological and structural properties. Polimery (Warsaw) 49, 819 - 827.

2. Janik, J., Lenart, S., Królikowski, W. \& Penczek, P.(2004) Polymer blends PET/PE-LD and PET/PP with a new compatibilizer. Polimery (Warsaw) 49, 432 - 439.

3. Bryan, E. \& Ray, S. (2009) Polymers a propertity database, CRC Press, Roca Baton.
4. Park, Y.J., Kang, Y.S. \& Park, Ch. (2005) Micropattering of semicrystalline PVDF solution. Eur. Polym. J. 41, $1002-$ 1012; DOI: 10.1016/j.eurpolymj.2004.11.022.

5. Yoon, L.K. \& Kim, B. K. (2000) Compatibility of poly(vinylidene fluoride) (PVDF) /Polyamide 12(PA12) blends. J. Appl. Polym. Sci. 78, 1374 - 1380; DOI;10.1002/10974628(20001114)78.

6. Sarkissova, M., Harratsa, Ch., Groeninckxa, G. \& Thomas, S. (2004) Design and characterisation of microfibrillar reinforced composite materials based on PET/ PA12 blends, Composites 35, 489 - 499; DOI:10.1016/ j.compositesa.2003.09.025.

7. Tang, T., Lei, Z. \& Huang, B.(1996) Studies on morphology and crystallization of polypropylene/polyamide 12 blends. Polymer 37, 3219 - 3226; DOI:10.1016/0032-3861(96)88465-5 .

8. Schneider, S., Drujon, X., Wittman, J.C. \& Lotz, B.(2001). Impact of nucleating agends of PVDF on the crystallization of PVDF/PMMA blends. Polymer 42, 8799 - 8806; DOI:10.1016/ S0032-3861(01)00349-4.

9. Liu, Z., Marechal, P. \& Jerome, R. (1997). Melting and crystallization of poly(vinylidene fluoride) blended with polyamide 6. Polymer 38, 5149 - 5153; DOI:10.1016/S00323861(97)00047-5.

10. Utracki, L.A. (2002). Polymer blends handbook. Kluwer Academic Pub. Dordrecht. 